\title{
Recent Advances in Cerebral Palsy with Special Reference to South Africa*
}

\author{
BEN EPSTEIN, M.B., B.Ch.(Rand), M.R.C.P.(London), D.C.H.(London). \\ Paediatrician, Pretoria.
}

Reprint from S.A. Medical Journal, Vol. 34, 13th February, 1960.

\begin{abstract}
$\mathrm{N}^{\text {or }}$ T long ago those in South Africa who interested hemselves in cerebral palsy were considered cranks and impractical visionaries. It was thought that to spend money on cerebral-palsied children was sheer waste, because nothing could be done for them. But times have changed, and in the last 10 years an entirely new concept has been and in the put only has the public attitude altered, thus giving the parents new hope, but the Central Government has recognized the justice of the claim for support and the medical profession is devoting more time to the study and treatment of this condition.

In this country, centres for the treatment of cerebral palsy have been established in Pretoria, Johannesburg, Cape Town have been establisher. These centres (schools), subsidized by the Department of Education, Arts and Science, provide by the Department of Ed treatment and schooling. They are all organizing residential facilities for platteland children. In addition, facilities are provided for some types of cerebral-palsied children in institutions such as Meerhof Hospital (Pretoria), the Hope Home (Johannesburg), Uplands Orthopaedic Centre (Pietermaritzburg), the Elizabeth Conradie School (Kimberley), the School for Vocational Training (Kimberley), and the Open Air School (Durban). There is a clinic and hostel for ineducable cerebral palsied children at Townsview, Johannesburg and a similar centre is being established in Pretoria in the near future. To date, the total number of children attending these institutions in South Africa is about 450 . Developments are taking place very quickly in this field and it is important that the medical profession should keep abreast of events.
\end{abstract}

\section{WHAT IS CEREBRAL PALSY ?}

Cerebral palsy is an unscientific term, and therefore difficult to define precisely. A year ago the International Study Group on Cerebral Palsy, which met in Oxford, England, discussed the definition for many hours (4 different definitions were put forward) and did not reach unaniminity. There has also been difficulty in translating the term into Afrikaans. It is only recently that serebraal verlamming was accepted as the most suitable term. In South Africa the following definitions and criteria has been adopted as standards for admission to a cerebral palsy school:

Cerebral palsy is a term used to designate any abnormal alteration of movement or motor function arising from a defect, injury or disease of the nervous tissue contained within the cranial cavity. The lesion may be localized or or diffuse and it may be caused by factors arising before, during, or after birth.

Among the signs and symptoms which may be present are the following: Motor dysfunction, convulsions, speech defects, mental retardation, behaviour disturbances of organic origin, and sensory losses, particularly in hearing and vision.

lt is recommended that the non-motor-handicapped brain-injured child, defined as follows by Strauss and Lehtinen, ${ }^{1}$ be considered under certain circumstances for admission to a cerebral palsy school: 'A brain-injured child is one who before, during or after birth has received an injury to, or suffered an infection of the brain. As a result of such organic impairment, defects of the neuromotor system may be present or absent. However, such a child may show disturbances in perception, thinking, and emotional behaviour, either separately or in combination.'

The criteria for admission are as follows:

1. All children suffering from cerebral palsy in terms of the above definition.

2. These children must be able to benefit by the corrective and educational treatment provided at the school.

3. The brain-injured child (Strauss and Lehtinen) may be admitted provided he can fit into and benefit by the school programme and is not aggressive.

4. Initial admission should be on a trial basis.

In England the 'Little Club' has recently suggested the following definition: ${ }^{2}$

Cerebral palsy is a persistent but not unchanging disorder of movement and posture, appearing in the early years of life, and due to a non-progressive disorder of the brain, the result of interference during its development.

Persistence of the infantile type of motor control such as may be seen in intellectually handicapped children, is not considered to be 'cerebral palsy'.

At the Oxford conference considerable differences of opinion on terminology and classification were voiced. Terminology and classification are important because scientific papers should be universally understood. During the demonstration of cases at the Radcliffe Infirmary there appeared to be disagreement even on clinical findings among the eminent experts present.

The classification most commonly used is that of the American Academy of Cerebral Palsy, which is as follows: (1) Spasticity (quadriplegia, paraplegia and hemiplegia), (2) athetosis, (3) ataxia, (4) tremor, (5) rigidity, (6) atonic form, (7) mixed form.

\section{DIAGNOSIS}

Early diagnosis is obviously important. There is, however, frequently an applicable and embarrassing passage of time between the voicing of the mother's fears about the normality of her child, and the specific diagnosis made by the doctor. Increasing knowledge is lessening this gap. It is, I think, essential that a medical practitioner who cannot answer a mother's questions should not hesitate to say, 'I do not know.' The comforting answer frequently given, 'There is nothing to worry about; your child will be quite well in two or three years' time,' is worse than useless. Honesty can only enhance the doctor's prestige; the parents will appreciate the referral of the patient to a doctor who has made a study of child development. In practice it inevitably happens that parents will, on their own initiative, seek another opinion if they get no helpful lead from their family doctor.

What are the criteria for the determination of early cerebral palsy? These are based on the studies of child development at various schools. Arnold Gesell and Myrtle McGraw, of the U.S.A., and Andre Thomas of France, have contributed greatly to the understanding of the abnormal, through their study of the normal development of the infant. The signs to look for are the ocular signs, the Moro response, the grasp reflex, the cardinal-points sign, the crossed-extension response, the righting reaction, the trunk-flexion reflex, and automatic stepping. One must be careful not to draw definite conclusions on the results of one examination, but

*Paper presented at the 42nd South African Medical Congress(M.A.S.A.), East London, C.P., September-October, 1959. 
these results may serve to warn one to keep a careful check on a suspected case; for example, a case born with a history of an abnormal pregnancy or labour or a case that has convulsions early in life. It should be possible to diagnose most cases of spasticity by the age of 6 months, and of athetosis by the age of 1 year.

Early diagnosis may be the greatest factor in the prevention of deformities and of the development of bad posture and gait. A great deal of attention is now being given to this problem. We can expect additions to our knowledge in the near future from the Andre Thomas School in Paris, where Minkowski and Mme. Saint-Anne Dorgassies and others are studying the early life of prematures and full-time neonates along clinical, histological and electro-encephalographic lines. The nutritionists, the biochemists and the geneticists are adding their quota to our information. A knowledge of the disorders of lipid metabolism, carbohydrate metabolism (as in galactosaemia) or amino-acid metabolism (as in phenylketonuria) may help to solve some of the problems associated with abnormalities of the cerebral functions. The Russians have drawn attention to the importance of enzymatic systems, such as cytochrome oxidase and succinic-acid dehydrogenase, in maintaining the normality of the brain. A great deal is being done, but much still eludes us.

\section{TREATMENT}

The treatment of cerebral palsy is still in a state of confusion. Perhaps the multiple problems presented, and the great variability of the physical and mental disabilities of the children, will always result in lack of unaniminity. A number of capable and intelligent individuals have worked out different methods of treatment, and have achieved some success. Different schools present completely divergent views, and sometimes success claimed by some cannot be repeated by others. Some use bracing, which others consider harmful. Some use corrective surgery, to which others are opposed. Some use techniques for breaking down various types of reflexes. Most schools use a combination of different methods, depending on the child's condition.

Phelps, ${ }^{3}$ one of the world's leading experts in cerebral palsy, enumerates the basic principles of the various methods:

1. Conditioning to establish reciprocal motion (Phelps).

2. Relaxation and motion from the relaxed position (Phelps).

3. Increasing awareness of contraction by resistive therapy (Kabat),

4. Utilization of residual patterns and of pathological reflexes (Temple Fay)

5. Inhibition of abnormal reflex patterns (Bobath).

6. Stimulation of contraction and consequent relaxation of antagonists (Rood).

7. Methods of Pohl, Swartz, Deavers, and Collis.

Conditioning is taught for the purpose of establishing fundamental patterns of motions automatically acquired by the normal baby and child. The sequence is that of the normal development of the infant.

Relaxation and motion, depending on the teaching of Jacobson. Progressive relaxation is taught by contraction and relaxation of the extremities. Numerous techniques are used to achieve this purpose.

Resistive therapy is utilized from the beginning of treatment. Instead of therapy of isolated muscles, patterns of mass movement are utilized, achieving maximum response in the muscles with each effort. Mechanical and manual methods are used to produce resistance.

Utilization of residual patterns and pathological reflexes. Temple Fay has been using primitive reflex patterns to enable movements to occur. He has utilized the amphibian and reptillian type of movement to achieve these results.

Inhibition of abnormal reflex patterns. Dr. and Mrs. Bobath have recently spent 6 weeks in Cape Town teaching therapists from all over South Africa their theories and techniques. A cerebral-palsied child develops many varied and abnormal patterns which interfere with the co-ordinated use of the trunk and extremities. Lesions at different levels of the central nervous system produce different abnormal reflex reactions, and Bobath techniques aim at inhibiting these reactions so that the child can relax. During the period of relaxation therapists, such as physio-, occupational or speech therapists, train the patient in their own sphere.

Stimulation of contraction and consequent relaxation of antagonists. This method was worked out by Miss M. S. Rood who operates on the two primary functions of muscles, viz. (a) movement by contraction with reciprocal inhibition of antagonists, and $(b)$ holding simultaneous contraction of antagonists and agonists.

While physiotherapy is the basic treatment, adjuncts to treatment are available, viz., (1) Bracing as practised by Phelps and Deavers in the U.S.A. and by Crosland in the U.K., (2) orthopaedic surgery, (3) drugs, and (4) special adjuncts.

\section{Orthopaedic Surgery}

Surgery has a definite place in treatment. For some time heavy attacks have been made on various surgical techniques. Some of them have been justifiably discarded, but others have been improved on.

Orthopaedic treatment may be operative or conservative. A great deal of its activity should be devoted to the prevention of deformities. No cerebral-palsy unit can function adequately without orthopaedic assistance, and without the help of specialists in physical medicine. The day-to-day control of treatment must be in their hands. Those centres that lack adequate help of this type must inevitably suffer.

G. A. Pollock, of Edinburgh, an eminent orthopaedic surgeon in this field, visited South Africa in 1955, when he participated in a symposium on cerebral palsy at the Medical Congress in Pretoria. He recommends ${ }^{4}$ that surgery should be used mainly in spastics, but occasionally in athetoids. Neurectomies such as Stoffel's operation have fallen into disrepute and are rarely used nowadays. Pollock advises that surgery should, in selected cases, be regarded as one of the means of facilitating and enhancing the effect of conservative treatment, rather than as a measure of desperation to be used only when conservative treatment has failed.

The common types of operation practised are: $(a)$ lengthening of the tendo Achilles, with capsulotomy if required, and (b) the Pollock slide operation on the gastrocnemius. Failure of these operations have been due to (i) inadequate excision or premature lengthening, (ii) lengthening of the tendo Achillis when tightness is present in the gastrocnemius alone, and (iii) the commonest cause, failure to maintain the correction obtained at operation by subsequent prolonged use of braces or splints and physiotherapeutic care.

Operations have also been devised for talipes calcaneus, talipes valgus, talipes varus, pes cavus, hallux valgus, flexor deformity of the knees, and the numerous other deformities occurring in the upper and lower limbs.

Neurosurgery has until recently had very little to offer. At present hemispherectomy ${ }^{5}$ is occasionally done for hemiplegia if associated with fits. Irving Cooper's work ${ }^{6}$ on chemo-pallidectomy for cases of chorea-athetosis may open the way for more extensive attacks on the primary lesion in the brain.

\section{Perceptual Defects}

One of the most important advances in the holistic conception of cerebral palsy is the increasing knowledge of the perceptual difficulties of these children. All cases of cerebral palsy are brain-injured-hence the admission of braininjured children without motor defect to our schools. The signs and symptoms depend on the area and extent of brain involvement. Large numbers of children have difficulties in which, apart from motor involvement, the power of perception is impaired. This handicap may give a wrong impression of a child's potentialities and, unless tackled along the correct pedagogic lines, will give rise to all kinds of difficulties for the child and the teacher. Fortunately, in South Africa 

we have some excellent and devoted teachers at our schools, implications, and are engaged in research into it.

Perceptual difficulties manifest themselves in different e ways, the most obvious being in the differentiate between various astereognosis and is unare subtle are the intellectual solids in his affected hand. More subtle are the is unable to difficulties - the aphasic child, and the one who ind thereby to view a picture in its proper perspective letters, and words. appreciate the significance of for mirror image, reversed, or These may appear in the form of mire is the child who draws upside-down. As an illustration there

a face with the eyes outside ${ }^{7}$ it was pointed out that agnosias At the Oxford conference it was pointed ox out the should be resulting from inadequate practice or experience should be distinguished from those resulting from specific cortical lesions (chiefly parietal). The former could be improved by special educational procedures more readily than the latter. The phrase 'body image' is becoming more frequently used, though it is not an exact reflection of what is meant. By 'body image' we mean a constant state of awareness of the position of the body; this is fundamental to normal development and behaviour. In the cerebral-palsied child its ultimate effect is largely determined by the age at which treatment is started because if it is tackled early on one may be able to overcome some of the difficulties. These children require a great deal of movement and the opportunity to crawl and roll and feel their own bodies. It is important for them to dress and undress and to do for themselves whatever they can. This type of direction is being extensively practised in Bristol by Dr. Grace E. Woods. ${ }^{8}$ Mme. Stella J. Albitreccia, of Paris, the famous speech therapist, has drawn up detailed tests for diagnosis and a plan for treatment of this very serious handicap.

\section{SOUTH AFRICAN WORK}

In South Africa a fair amount of experimental and research work is being carried out, but not all of it has been published. Significant contributions to our knowledge have been made by two very successful courses organized by the Cerebral Palsy Division of the National Council for the Care of Cripples in South Africa. One was on the 'Education of cerebral palsy children,"10 and the other was on the "Therapies in cerebral palsy.'11 Prof. B. F. Nel, ${ }^{12}$ Director, Child Guidance Clinic, University of Pretoria, has published a book on Die Serebraalgestremde Kind, which is a study of the physical and psychological handicaps of the braininjured child. Several logopaedic students at the University of Witwatersrand have handed in M.A. theses on the speech problems of the cerebral-palsied child. The most important contribution has just been published by the National Bureau of Educational and Social Research of the Department of Education, Arts, and Science. This is A Survey of the Physical and Mental Status of Cerebral Palsied European Children at School in the Union of South Africa, ${ }^{13}$ a book written by Dr. C. H. de C. Murray, Inspector of Psychological Services in the Department of Education, Arts, and Science, and formerly Principal of the Pretoria School for Cerebral Palsy.

This survey, which covers also adults with cerebral palsy, and which was undertaken primarily at the request of the National Council for the Care of Cripples in South Africa, obtained information, by means of detailed questionnaires, about numbers, age, sex, home language, diagnosis, limbs involved, degree of disability, personal traits, intellectual ability, and scholastic status. A survey of this kind is very complicated and difficult to carry out because of the number of individuals on whom one has to draw for information; terminology, classification, and outlook on cerebral palsy varies, and correlation is not easy. Dr. Murray has performed a gigantic task; his study is a classic, and bears fayourable comparison with similar studies made elsewhere. For those of us who are working in this field in South Africa it is a source of invaluable information that will guide us in determining a course of action for the increasing numbers of affected children who, in the near future, will be leaving our schools. There is a great deal of statistical information that has already been presented. Out of 380 cases at the schools, 222 were males, and 158 females. (On this basis hostel accomodation is being arranged). Dr. Murray put these figures to a statistical test and found that this sex inequality was not significant and was due to chance. He also found that in the hands of a competent psychologist the IQ rating, in spite of all the difficulties in testing, was reasonably accurate; he subsequently confirmed this by the critical test of children's performances at school.

One serious gap in South Africa is the lack of facilities for the treatment of the African cerebral-palsied child. We do not know how many children are involved; my own attempts in Pretoria to make a sample survey of an area like Lady Selbourne proved a failure, even with the help of an African social worker. There were very few cases of cerebral palsy to be found, owing, I think, to two factors, viz. (1) early death due to difficulties in rearing a child under primitive living conditions, and (2) the custom of Africans in the towns of sending such children away to the country. This custom is now a diminishing factor, for millions of Africans have become detribalized and established in the urban areas. For those Africans who present themselves for treatment no special facilities are available in the large urban areas. At Edenvale Hospital, Johannesburg, cases of cerebral palsy are admittted to the wards for diagnosis and investigation. Physiotherapy and occupational therapy are begun and the mothers are shown how to carry on with such treatment at home, and asked to report back regularly as out-patients to the Department of Physical Medicine, under Dr. Cyril Adler. A proper school for African patients has been started in Umtata by the Glen Avent Roman Catholic Mission, and there are prospects of this becoming a big school with financial support from overseas.

\section{CONCLUSION}

In this very superficial survey of recent advance in cerebral palsy I have inevitably had to limit myself to a few aspects of the problem; the field is far too wide to be covered in one paper. I should like to conclude with an appeal to the medical profession in South Africa to accept the fact that rehabilitation (or, as some people call it, habilitation) has become an important facet of cerebral palsy. The profession must, by the nature of the condition, co-operate closely with nonmedical personnel such as teachers, social workers, and employment officers, and with 'near-medical' personnel such as psychologists and physio-, occupational and speech therapists. The cerebral-palsy patient needs the active assistance of paediatricians, orthopaedic surgeons, specialists in physical medicine, psychiatrists, neurologists, neurosurgeons, ophthalmologists, and audiologists. The general practitioner plays an important part in this set-up because it is to him that the first approach to diagnosis will be made.

There are at least a thousand cases of cerebral palsy among the European section of our population, and there must be many thousands among the non-European section; it is therefore important to teach our medical students about this condition.

\section{REFERENCES}

1. Strauss, A. A. and Lehtinen, L. E. (1947): Psychology and Education of the Brain-Injured Child, vol. 1, p. 4. New York: Grune Stratton.

Mackeith R Cor Palsy Bull., 5, 23.

3. Phelps, W. M. In Illingsworth, R. S. ed. (1958): Recent Advances in Cerebral Palsy, p. 252. London: Churchill.

4. Pollock, G. A. In lllingworth, op. cit. ${ }^{3}$ p. 287 .

5. Krynauw R. A. (1950): J. Neurol, Neurosurg. Psychiat., 13, 243.

6. Cooper I S. (1956): The Neurological Alleviaiton of Parkinsonism. Springfield, IIl: Charles C. Thomas.

Report on Oxford Conference (1958): Cer. Palsy Bull., 4, 4.

7. Report on Ox (1958): bid

9. Albitreccia, S. I. (1958): Ibid., 4, 12.

9. Albitreccia, S. I. (1958): Ibid., 4, 12 . (1956) Johannesburg. National

0. Education of Cerebral Palsy Children (1956)

Council for the Care of Cripples in S. A. Therapies in Cerebral Palsy (1957)

12. Nel B F. (1955): Die Serebraalgestremde Kind. Pretoria: J. L. van Schaik.

13. Murray, C. H. de C. (1959): A Survey of the Physical and Mental Status of Cerebral Palsied European Children at School in the Union of South Africa. Pretoria: National Bureau of Educational and Social Research. 